\title{
Development and feeding behavior of Helicoverpa armigera (Hübner) (Lepidoptera: Noctuidae) on different sunflower genotypes under laboratory conditions
}

\author{
Caio Cesar Truzi ${ }^{1}$ - Natalia Fernanda Vieira ${ }^{1} \cdot$ Valéria Lucas de Laurentis $^{1}$. \\ Alessandra Marieli Vacari ${ }^{1} \cdot$ Sergio Antonio De Bortoli ${ }^{1}$
}

Received: 28 July 2016/Accepted: 29 April 2017/Published online: 12 May 2017

(C) Springer Science+Business Media Dordrecht 2017

\begin{abstract}
The aim of this study was to assess the biological aspects and food preferences of Helicoverpa armigera fed different sunflower genotypes and an artificial diet. Tests were performed under multiple-choice and no-choice conditions to evaluate the biological characteristics of $H$. armigera. In addition, the biological data obtained were used to determine parameters of fertility life tables. The results showed that $H$. armigera does not have a feeding preference among the sunflower genotypes tested. The larval period on sunflower ranged from 15.0 to 16.2 days. The maximum fecundity on sunflower was 542.6 eggs/female and that on the artificial diet was 794.5 eggs/female. In general, insects feeding on Helio 250 consumed greater quantities of leaves, had higher survival until the end of the pupal stage, displayed high population growth rates, and had low population doubling times, suggesting that in the field populations will achieve greater population densities when fed on Helio 250. Insects that fed on CF101 consumed smaller leaf areas, had lower survival until the end of the pupal stage, lower fertility rates, and lower population growth rates, and may also have displayed lower population densities and smaller reductions in field productivity. This insect developed best on an artificial diet in comparison to sunflower genotypes studied.
\end{abstract}

Keywords Insect biology $\cdot$ Helianthus annuus $\cdot$ Integrated pest management

Handling Editor: Joe Louis.

Alessandra Marieli Vacari

amvacari@gmail.com

1 Department of Plant Protection, Laboratory of Biology and Insect Rearing (LBIR), São Paulo State University, 14884-900 Jaboticabal, SP, Brazil

\section{Introduction}

Sunflower, Helianthus annuus L. (Asteraceae), stands out as one of the four largest oil-producing crops in the world, along with soybeans, rapeseed, and cotton (USDA 2015). Global production of sunflower seeds in the 2014-2015 harvest was estimated at approximately 40 million tons, with the largest producers being Ukraine, countries in the European Union, Russia, Argentina, and Turkey (USDA 2015). In Brazil, sunflower production in 2014-2015 was estimated at 144,500 tons in a planted area of over 90,000 hectares. The state of Mato Grosso is Brazil's largest sunflower producer, accounting for $78.1 \%$ of the nation's production (CONAB 2015). In Brazil, sunflowers are grown between the growing seasons of major crops, such as soybeans and corn, and therefore pests occurring in these crops may also attack sunflower (Lazzarotto et al. 2005).

As a pest of agriculture, Helicoverpa armigera (Hübner) (Lepidoptera: Noctuidae) larvae generally feed on plant stems, leaf blades, and reproductive structures (Cunningham et al. 1999), and can cause severe reductions in crop productivity. Plants that are defoliated between 48 and 68 days old may result in $72-85 \%$ reduced crop production (Paro Júnior and Nakano 1976). On average, 50-75\% of flowering plants are susceptible to defoliation, reducing grain yield by 43.6-91.1\% (Villas Bôas and Moscardi 1985).

In Brazil, H. armigera is on the list of quarantine pests prepared by the Ministry of Agriculture, Livestock, and Supply (MAPA-Agrofit 2015); however, there have been reports of this pest from the states of Goiás, Mato Grosso, and Bahia in soybean, cotton, and volunteer soybean, respectively (Czepak et al. 2013). Additionally, this pest has been reported from the following states and crops: Mato Grosso do Sul, Minas Gerais, Bahia, Pará, Paraná, São Paulo, and Piauí in soybean, corn, cotton, tomato, and citrus (Gabriel 2013; Bueno et al. 2014; 
Pratissoli et al. 2015). Currently, several chemical and biological insecticides have been registered for the control of $H$. armigera (Agrofit 2017), and damage caused to farmers has been estimated at US\$2.8 billion (Gottems 2014).

Studying the development of $H$. armigera in four sunflower hybrids, Sharma and Singh (2001) observed five larval instars over the course of development lasting between 9.1 and 15.2 days. The duration of the pupal period varied between 8.25 and 12.0 days and males weighed less $(276.0 \mathrm{mg})$ than females $(287.05 \mathrm{mg})$. Adult females survived longer with a maximum longevity of 7.3 days, whereas males had lower values, with a maximum longevity of 6.0 days. Eggs hatched between 2.7 and 3.5 days after being laid. Thus, the entire lifecycle of $H$. armigera ranged from 32.5 to 35.6 days.

The use of chemical insecticides is the main method employed to control $H$. armigera (Building and Arhabhata 2007), but insecticides are detrimental to the environment. Insecticides can kill or repel bees during sunflower pollination causing a reduction in grain production (Baptista et al. 2009; Inácio et al. 2003).

Thus, the use of resistant and/or less susceptible and/or less susceptible plants, are of great importance in Integrated Pest Management (IPM) (Abrol 2013). Pest-resistant plants is a control method used in IPM to decrease the pest populations below levels economic damage without causing pollution or disturbance to the ecosystem, and without causing further loss to the farmer (Lara 1991). Thus, the objective of this study was to evaluate the biological aspects and feeding behavior of $H$. armigera on different sunflower genotypes and an artificial diet under laboratory conditions.

\section{Materials and methods}

\section{Plant material and insects}

Seeds of the sunflower (H. annuus) genotypes Helio 251 and CF 101, as well as the high oleic genotypes Helio 250, Helio 253, and ADV 5504, were sown in an experimental area $\left(21^{\circ} 15^{\prime} 17^{\prime \prime} \mathrm{S} 48^{\circ} 19^{\prime} 20^{\prime \prime} \mathrm{W}\right)$ fertilized with $350 \mathrm{~kg} \mathrm{ha}^{-1}$ of 08-28-16 fertilizer. Topdressing was conducted 30 days after seedling emergence with $100 \mathrm{~kg} \mathrm{ha}^{-1}$ of urea. The experimental area was weeded by hand and drip irrigated.

The insects used in the study were derived from Promip, located in Engenheiro Coelho, SP. These larvae were collected from soybean plantations in the soybean crops in the county of Luis Eduardo de Magalhães, BA, and from tomato in Goiania, GO.

The $H$. armigera colony was maintained under laboratory-controlled conditions (temperature $=25 \pm 1{ }^{\circ} \mathrm{C}$, relative humidity $=70 \pm 10 \%$, and photoperiod of $12-\mathrm{h}$ light: 12-h dark) on an artificial diet modified from Greene et al. (1976).
Feeding preference of Helicoverpa armigera larvae by sunflower genotype (multiple-choice)

The experimental design consisted of randomized blocks arranged in split plots with ten replications. Treatments consisted of five sunflower genotypes (e.g., Helio 250, Helio 251, Helio 253, CF101, and ADV5504). Each treatment was evaluated at nine time intervals (e.g., 5, 15, $25,35,45,60,1440,2880$, and $4320 \mathrm{~min}$ ) after the larvae were released.

At 40 days post emergence, sunflower leaves were collected, taken to the laboratory, soaked in 5\% sodium hypochlorite for $5 \mathrm{~min}$, washed in tap water, and blotted with paper towels to remove excess water.

Leaf disks measuring $2.0 \mathrm{~cm}$ in diameter were cut from the leaves of each genotype, arranged equidistantly on petri dishes $(15.0 \mathrm{~cm}$ diameter $\times 2.0 \mathrm{~cm}$ height $)$, and lined with filter paper that had been moistened with distilled water. Ten first instar $H$. armigera were then released at the center of each petri dish with backlog in the number of attracted insects on each leaf disk in each evaluation time. The larvae were recorded in each particular genotype, if the larvae were present on the disk. We also evaluated several times to determine the most suitable for use in future tests.

\section{Feeding preference of Helicoverpa armigera larvae by sunflower genotype (no-choice)}

The experimental design was completely randomized with ten replications and five treatments (e.g., Helio 250, Helio 251, Helio 253, CF 101, and ADV 5504). After 40 days post emergence, leaves were collected, taken to the laboratory, soaked in 5\% sodium hypochlorite for $5 \mathrm{~min}$, washed in tap water, and blotted with paper towels to remove excess water.

Leaf disks measuring $2.0 \mathrm{~cm}$ in diameter were removed from the leaves of each genotype and were placed in the center of a petri dish $(6.0 \mathrm{~cm}$ diameter $\times 2.0 \mathrm{~cm}$ height $)$ and lined with filter paper that had been moistened with distilled water. In each plate was a single leaf disk. Ten first instar $H$. armigera were released on the filter paper and the number of larvae attracted to the leaf disk was recorded at each evaluation interval (e.g., 5, 15, 25, 35, 45, 60, 1440, 2880, and $4320 \mathrm{~min}$ ) post release. We also evaluated several times to determine the most suitable for use in future tests.

\section{Biological aspects of Helicoverpa armigera fed different sunflower genotypes and an artificial diet}

These experiments were conducted under laboratory-controlled conditions of temperature $\left(25 \pm 1{ }^{\circ} \mathrm{C}\right)$, relative humidity $(70 \pm 10 \%)$, and photoperiod (12-h light/12-h dark). 
The experimental design was completely randomized with fifty replicates, five treatments (e.g., Helio 250, Helio 251, Helio 253, CF 101, and ADV 5504), and an artificial diet modified from Greene et al. (1976).

For each sunflower genotype, 50 newly hatched first instar larvae $(<24 \mathrm{~h})$ were placed in petri dishes $(6 \mathrm{~cm}$ diameter $\times 2 \mathrm{~cm}$ height) lined with filter paper that had been moistened with distilled water, and monitored until the larvae reached the pupal stage. Leaf disks that had been washed with $5 \%$ sodium hypochlorite, cleaned in running water, and then dried were supplied to the larvae daily. The following biological parameters were determined: larval period, larval viability, pupal period, pupal viability, and the leaf area consumed by larvae using a leaf area meter (Model CI-202, Bio-Science ICD).

For the artificial diet, 50 newly hatched first instar larvae $(<24 \mathrm{~h})$ were placed in petri dishes $(6 \mathrm{~cm}$ diameter $\times 2 \mathrm{~cm}$ height) and monitored until the larvae reached the pupal stage. Cubes of artificial diet were replaced after approximately $80 \%$ had been consumed. The biological parameters evaluated for larvae fed the artificial diet were the same described above, except for leaf area, which was not applicable.

Pupae were separated by sex and were weighed $24 \mathrm{~h}$ after reaching the pupal stage.

To house emerging adults, 15 cylindrical cages of PVC $(10.0 \mathrm{~cm}$ diameter $\times 20.0 \mathrm{~cm}$ height $)$ were constructed for each treatment. Each cage was closed at the top with voile fabric, lined with paper towels, and supported on a plastic cover $(15.0 \mathrm{~cm}$ diameter $\times 2.0 \mathrm{~cm}$ height $)$ lined with filter paper. Two adult $H$. armigera that had emerged the same day were released in each cage. Adults were fed with a $10 \%$ honey-water mixture on a piece of soaked cotton packed inside a plastic top $(3.0 \mathrm{~cm}$ diameter $\times 1.5 \mathrm{~cm}$ height). Daily observations were conducted for the following parameters: pre-oviposition period, oviposition period, female fecundity (i.e., number of eggs per female), and longevity of male and female adults.

The duration of the embryonic period and the fertility of the egg (i.e., viability) samples were analyzed by observing 50 eggs in each treatment. Eggs were placed in petri dishes $(15.0 \mathrm{~cm}$ diameter $\times 2.0 \mathrm{~cm}$ height). The number of hatched larvae and the time required for hatching were recorded.

We used the biological parameters obtained to construct fertility life tables according to Birch (1948), Silveira Neto et al. (1976), Southwood (1978), and Price (1984). The values used for the life tables are listed as follows: $x=$ age of parental females; $1 \mathrm{x}=$ life expectancy to age $x$, expressed as a fraction per female; $\mathrm{mx}=$ specific fertility or number of offspring produced per female at age $x$; and $\mathrm{lx} \cdot \mathrm{mx}=$ total number of females at age $x$. The growth parameters resulting from life tables are as follows: $R_{0}=$ net rate of population growth; $T=$ mean generation time; $r_{\mathrm{m}}=$ intrinsic rate of increase; and $\lambda=$ finite rate of increase. In addition to these parameters, we also determined $D t$, which is the time required for the population to double in number (Krebs 1994).

The growth parameters (e.g., $R_{0}, T, r_{\mathrm{m}}, \lambda$, and $D t$ ) were calculated using the following equations:

$R_{0}=\sum(1 \mathrm{x} \cdot \mathrm{mx})$

$T=\sum(\mathrm{x} \cdot \mathrm{lx} \cdot \mathrm{mx}) / \sum(\mathrm{lx} \cdot \mathrm{mx})$

$r_{\mathrm{m}}=\ln R_{0} / T$

$\lambda=e^{r m}$

$D t=\ln (2) / r_{\mathrm{m}}$.

\section{Statistical analysis}

Frequency data of $H$. armigera in each treatment were analyzed using PROC FREQ and interpreted using the Chisquare test $(P<0.05)$. All analyses were conducted using SAS software (2002).

Leaf area consumed, egg incubation period, and the longevity of male and female $H$. armigera relative to the different sunflower genotypes and the artificial diet were subjected to Kolmogorov and Bartlett tests to determine normality and homogeneity of variance.

Data from the oviposition period were transformed by the root of $x+0.5$ to meet the requirements of the analysis of variance (ANOVA) and then analyzed using PROC ANOVA. Means were compared by Tukey's test $(P<0.05)$.

Data for the larval period, pupal period, weight of pupae, fecundity of females, pre-oviposition period, and fertility of eggs did not meet the requirements for the ANOVA and instead were compared using the KruskalWallis test (i.e., PROC Npar1way).

Survival data of the larval and pupal periods were analyzed using the Chi-square test (i.e., PROC FREQ) $(P<0.05)$. All analyses were conducted using SAS software (2002).

Population parameters of fertility life tables were estimated according to the Jackknife method for estimating the confidence intervals of the parameters and for allowing comparison between treatments as described by Maia et al. (2000). Estimates were conducted using SAS software (2002). 


\section{Results}

\section{Feeding preference of Helicoverpa armigera larvae by sunflower genotype (multiple-choice)}

The average percentage of first instar larvae feeding on sunflower genotypes increased as a function of time. After $35 \mathrm{~min}$, the number of larvae did not change among times within a genotype, with values ranging from $10.3 \%$ to $14.6 \%$ (Table 1). This result suggests that $35 \mathrm{~min}$ was the shortest time for $H$. armigera to discriminate between sunflower genotypes. We also evaluated several times to determine the most suitable for use in future tests.

There was no significant difference between the Helio 251 and CF101 genotypes despite Helio 251 attracting half as many larvae (26.3\% and $13.1 \%$, respectively) (Table 2).

\section{Feeding preference of Helicoverpa armigera larvae by sunflower genotype (no-choice)}

When first instar $H$. armigera larvae had no choice between sunflower genotypes, the time required for evaluation was $60 \mathrm{~min}$ (Table 3) and was higher than that found for the multiple-choice test (e.g., $35 \mathrm{~min}$ ). Both of these time periods corresponded to the intervals with the highest percentages of larvae. Between the time intervals of 60 and 4320 min, no significant differences were observed among times considering all the genotypes, with values ranging between 11.9 and $14.0 \%$.

The percentages of larvae in the no-choice tests showed no significant difference between sunflower genotypes at all evaluated times, with averages ranging from 17.4 to $22.3 \%$ of larvae per genotype (Table 4 ).

Table 1 Percentage of Helicoverpa armigera larvae on each sunflower genotype by time interval in multiple-choice tests
Table 2 Percentage of Helicoverpa armigera larvae on each sunflower genotype in multiple-choice tests at all evaluated times

Table 3 Percentage of Helicoverpa armigera larvae on each sunflower genotype by time interval in no-choice tests

Table 4 Percentage of Helicoverpa armigera larvae on each sunflower genotype in nochoice tests at all evaluated times

\begin{tabular}{lc}
\hline Time $(\mathrm{min})$ & Larvae $(\%)$ \\
\hline 5 & $5.2 \pm 1.22 \mathrm{c}^{\mathrm{a}}$ \\
15 & $7.2 \pm 1.54 \mathrm{c}$ \\
25 & $8.4 \pm 1.43 \mathrm{bc}$ \\
35 & $10.3 \pm 2.56 \mathrm{abc}$ \\
45 & $13.0 \pm 2.21 \mathrm{ab}$ \\
60 & $13.3 \pm 3.46 \mathrm{ab}$ \\
1440 & $13.9 \pm 2.43 \mathrm{ab}$ \\
2880 & $14.6 \pm 2.54 \mathrm{ab}$ \\
4320 & $14.0 \pm 3.26 \mathrm{a}$ \\
\hline
\end{tabular}

${ }^{a}$ Mean \pm standard error values followed by the same letter in the column are not significantly different (Tukey's test, $P>0.05)$ time.

\begin{tabular}{ll}
\hline Genotypes & Larvae (\%) \\
\hline CF101 & $26.3 \pm 2.78 \mathrm{a}^{\mathrm{a}}$ \\
ADV5504 & $22.2 \pm 1.75 \mathrm{a}$ \\
Helio 250 & $21.2 \pm 2.43 \mathrm{a}$ \\
Helio 253 & $17.2 \pm 0.82 \mathrm{a}$ \\
Helio 251 & $13.1 \pm 1.60 \mathrm{a}$ \\
\hline
\end{tabular}

${ }^{a}$ Mean \pm standard error values followed by the same letter in the column are not significantly different (Tukey's test, $P>0.05$ )

\begin{tabular}{lc}
\hline Time $(\mathrm{min})$ & Larvae $(\%)$ \\
\hline 5 & $7.4 \pm 1.29 \mathrm{~d}^{\mathrm{a}}$ \\
15 & $9.1 \pm 1.95 \mathrm{~cd}$ \\
25 & $9.9 \pm 2.28 \mathrm{bc}$ \\
35 & $10.6 \pm 2.76 \mathrm{bc}$ \\
45 & $11.2 \pm 3.22 \mathrm{bc}$ \\
60 & $11.9 \pm 2.23 \mathrm{ab}$ \\
1440 & $14.0 \pm 1.02 \mathrm{a}$ \\
2880 & $14.0 \pm 2.26 \mathrm{a}$ \\
4320 & $11.9 \pm 1.65 \mathrm{ab}$ \\
\hline
\end{tabular}

${ }^{a}$ Mean \pm standard error values followed by the same letter in the column are not significantly different (Tukey's test, $P>0.05$ )

\begin{tabular}{ll}
\hline Genotypes & Larvae $(\%)$ \\
\hline CF101 & $22.3 \pm 3.75 \mathrm{a}^{\mathrm{a}}$ \\
Helio 250 & $20.6 \pm 1.92 \mathrm{a}$ \\
ADV5504 & $20.4 \pm 3.11 \mathrm{a}$ \\
Helio 251 & $19.4 \pm 2.81 \mathrm{a}$ \\
Helio 253 & $17.4 \pm 1.39 \mathrm{a}$
\end{tabular}

${ }^{a}$ Mean \pm standard error values followed by the same letter in the column are not significantly different (Tukey's test, $P>0.05$ )

\section{Biological aspects of Helicoverpa armigera fed different sunflower genotypes and an artificial diet}

The results obtained for the larval period of $H$. armigera suggested that there was an influence of the different sunflower genotypes and artificial diet on developmental parameters. Larvae fed with leaves of Helio 251 and the artificial diet had the shortest larval period (ranging from 14.6 to 15.3 days) (Table 5), thereby favoring the development, contributing to a reduction in the duration of the lifecycle, and increasing the number of generations over 
Table 5 Duration and leaf consumption of the larval period of Helicoverpa armigera on sunflower genotypes and an artificial diet

\begin{tabular}{lll}
\hline Diets & Leaf consumption $\left(\mathrm{cm}^{2}\right)$ & Larval period (days) \\
\hline ADV5504 & $178.2 \pm 3.79 \mathrm{~b}^{\mathrm{a}}$ & $15.3 \pm 0.33 \mathrm{abc}$ \\
CF101 & $122.1 \pm 4.33 \mathrm{c}$ & $16.2 \pm 0.18 \mathrm{a}$ \\
Helio 250 & $206.6 \pm 4.58 \mathrm{a}$ & $15.8 \pm 0.33 \mathrm{ab}$ \\
Helio 251 & $129.5 \pm 3.34 \mathrm{c}$ & $15.0 \pm 0.23 \mathrm{bc}$ \\
Helio 253 & $169.4 \pm 4.49 \mathrm{~b}$ & $15.9 \pm 0.29 \mathrm{ab}$ \\
Artificial diet & - & $14.6 \pm 0.21 \mathrm{c}$
\end{tabular}

${ }^{\text {a }}$ Mean \pm standard error values followed by the same letter in the column are not significantly different (Tukey's test, $P>0.05$ )

Leaf consumption by $H$. armigera was significantly higher in Helio 250 with an average area of $206.6 \mathrm{~cm}^{2}$. In the genotypes ADV5504 and Helio 253, consumption was intermediate, with the values of 178.2 and $169.4 \mathrm{~cm}$, respectively. The genotypes Helio 251 and CF101 had the lowest average leaf areas consumed, with the values of 129.5 and $122.1 \mathrm{~cm}^{2}$, respectively (Table 5).

When we compared preference data with leaf consumption, we found that genotypes showed similar percentage of larvae (Table 2), but the genotypes CF 101 and Helio 251 showed the lowest area of leaf consumption (Table 5), suggesting resistance to these genotypes by influencing the feeding process.

The survival of $H$. armigera larvae did not differ among the sunflower genotypes or the artificial diet. However, survival until the end of the pupal stage was significantly higher for insects who consumed artificial diet (94.0\%) (Fig. 1). Only the Helio 250 genotype with $50.0 \%$ pupal survival was similar to the artificial diet. All other genotypes had significantly lower pupal survival percentages,

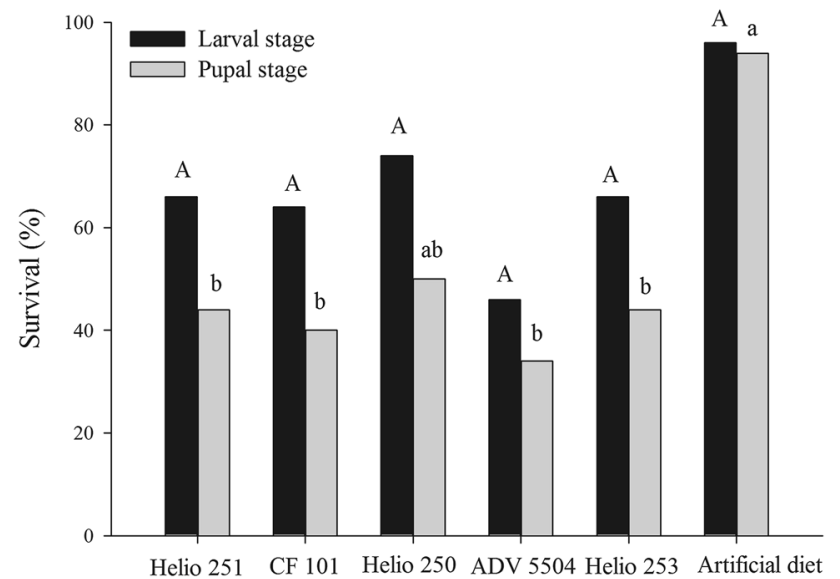

Fig. 1 Survival of the larval and pupal stages of Helicoverpa armigera on sunflower genotypes and an artificial diet. Different capital and lower case letters indicate significant differences in larval and pupal survival, respectively $(P<0.05)$ with values ranging between 34.0 and $44.0 \%$ (Fig. 1). These values are significantly lower than those found by Sharma and Singh (2001), where pupal survival ranged between 65.0 and $93.3 \%$.

Low survival at the end of the pupal stage may be related to a nutritional deficiency in certain sunflower genotypes, as deformed pupae were observed in these treatments. According to Moretti and Parra (1983), low pupal survival in noctuid moths has been attributed to low nutritional quality.

There was no influence of sunflower genotypes or artificial diet on the pupal period of $H$. armigera (11.5-12.1 days) (Table 6).

Pupal weights had no difference among sunflower genotypes. The weights of males $(346.7 \mathrm{mg})$ and females $(354.6 \mathrm{mg})$ fed the artificial diet were not significantly different from one another. In all sunflower genotypes, the pupal weights of males and females were significantly similar, ranging from 280.9 to $319.1 \mathrm{mg}$ (Table 6). In both the sunflower genotypes and artificial diet, pupal weights of females were higher than those of males.

The values measured by Sharma and Singh (2001) also showed increased pupal weight for females that fed on sunflower. In their study, the largest observed weights for a male and a female pupa were $276.0 \mathrm{mg}$ and $287.05 \mathrm{mg}$, respectively.

Male $H$. armigera larvae that fed on sunflower genotypes showed no significant differences in longevity, which ranged from 7.5 days for ADV5504, to 8.2 days for Helio 253. There was also no significant difference between sunflower genotypes and the artificial diet where insects had an average longevity of 8.3 days (Table 7).

Females survived longer compared to males in all the treatments. However, there were no significant differences between sunflower genotypes and the artificial diet. Insects fed the sunflower genotypes had longevity values ranging from 8.2 to 9.5 days, whereas those fed the artificial diet averaged 9.5 days (Table 7).

The pre-oviposition and oviposition periods were not significantly different between sunflower genotypes and the artificial diet. Regarding the pre-oviposition period, there were no significant differences between sunflower genotypes and the artificial diet. Female moths fed the Helio 253 genotype took 1.3 days on average to start ovipositing, whereas those fed the ADV5504 genotype took 1.5 days, and those fed either CF101, Helio 250, or Helio 251 took an average of 1.6 days. Insects fed the artificial diet had an average pre-oviposition period of 1.9 days (Table 8).

For the oviposition period, there were no significant differences between sunflower genotypes and the artificial diet. Values ranged from 6.7 days for the insects from the ADV5504 genotype, to 7.7 days for insects fed the Helio 251 genotype and the artificial diet (Table 8). 
Table 6 Duration of the pupal stage and average weight of Helicoverpa armigera pupae reared on sunflower genotypes and an artificial diet

\begin{tabular}{llll}
\hline Diets & Pupal period (days) & \multicolumn{2}{l}{ Weight of pupae (mg) } \\
\cline { 3 - 4 } & & Male & Female \\
\hline ADV5504 & $11.9 \pm 0.16 \mathrm{a}^{\mathrm{a}}$ & $280.9 \pm 8.78 \mathrm{~b}$ & $293.7 \pm 4.72 \mathrm{~b}$ \\
CF101 & $11.5 \pm 0.21 \mathrm{a}$ & $295.5 \pm 13.14 \mathrm{~b}$ & $319.1 \pm 8.00 \mathrm{~b}$ \\
Helio 250 & $11.5 \pm 0.18 \mathrm{a}$ & $288.9 \pm 9.23 \mathrm{~b}$ & $290.9 \pm 8.31 \mathrm{~b}$ \\
Helio 251 & $11.9 \pm 0.19 \mathrm{a}$ & $291.4 \pm 7.36 \mathrm{~b}$ & $318.0 \pm 6.53 \mathrm{~b}$ \\
Helio 253 & $11.9 \pm 0.20 \mathrm{a}$ & $291.6 \pm 8.03 \mathrm{~b}$ & $291.7 \pm 7.15 \mathrm{~b}$ \\
Artificial Diet & $12.1 \pm 0.16 \mathrm{a}$ & $346.7 \pm 8.54 \mathrm{a}$ & $354.6 \pm 10.72 \mathrm{a}$ \\
\hline
\end{tabular}

${ }^{a}$ Mean \pm standard error values followed by the same letter in the column are not significantly different (Tukey's test, $P>0.05$ )
Table 7 Longevity (days) of male and female Helicoverpa armigera reared on sunflower genotypes and an artificial diet

\begin{tabular}{lll}
\hline Diets & Male longevity (days) & Female longevity (days) \\
\hline ADV5504 & $7.5 \pm 1.08 \mathrm{a}^{\mathrm{a}}$ & $8.2 \pm 1.32 \mathrm{a}$ \\
CF101 & $7.8 \pm 1.02 \mathrm{a}$ & $9.1 \pm 0.90 \mathrm{a}$ \\
Helio 250 & $7.6 \pm 1.09 \mathrm{a}$ & $8.9 \pm 1.03 \mathrm{a}$ \\
Helio 251 & $8.1 \pm 0.91 \mathrm{a}$ & $9.5 \pm 1.73 \mathrm{a}$ \\
Helio 253 & $8.2 \pm 0.84 \mathrm{a}$ & $8.7 \pm 1.31 \mathrm{a}$ \\
Artificial diet & $8.3 \pm 0.80 \mathrm{a}$ & $9.5 \pm 0.84 \mathrm{a}$
\end{tabular}

${ }^{a}$ Mean \pm standard error values followed by the same letter in the column are not significantly different (Tukey's test, $P>0.05$ )

Sharma and Singh (2001) found higher values for the pre-oviposition period, ranging from 2.0 to 3.5 days, while the oviposition period was generally shorter, with a maximum value of 3.7 days.

Female fecundity was not significantly different between larvae fed sunflower genotypes and those fed the artificial diet. The fecundity of females fed the artificial diet was 794.5 eggs per female. Fecundity ranged from 439.4 to 542.6 eggs per female relative to the sunflower genotype (Table 9).

According to Sharma and Singh (2001), fecundity values can range from 386.50 to 749.00 eggs per female, whereas Shanower and Romeis (1999) mentioned that the oviposition capacity of $H$. armigera can reach 3000 eggs.
The incubation period showed no significant difference among treatments, with values ranging from 2.9 days in Helio 250 and Helio 253 genotypes, to 3.0 days in the genotypes ADV5504, CF101, and Helio 251. The incubation period for the artificial diet was 2.8 days (Table 10).

Egg fertility values were significantly different between treatments. Eggs laid by females reared on the artificial diet had an average survival of $73.8 \%$. For females reared on sunflower, the Helio 250 and Helio 251 genotypes showed the highest values of $57.7 \%$ and $56.2 \%$, respectively (Table 10). Sharma and Singh (2001) reported that the viability of eggs varied from 87.34 to $97.67 \%$, which are higher values than those found in this study.

The fertility life table was constructed with the results obtained for the biological parameters of $H$. armigera and showed differences between the parameters evaluated. The net reproductive rate $\left(R_{0}\right)$ was greater when the larvae were fed the artificial diet, producing 255.9 females per female in each generation. For sunflower genotypes, the highest $R_{0}$ values were found for CF101, Helio 250, Helio 251, and Helio 253 that had values between 83.5 and 135.6 females per female in each generation. In relation to the average generation time $(\mathrm{T})$, the lowest values were found for artificial diet (28.9 days) and sunflower genotype ADV5504 (29.5 days), while the other genotypes showed higher values compared to artificial diets ranging from 30.5 to 31.4 days. The intrinsic rate of increase $\left(r_{\mathrm{m}}\right)$ and the finite rate of increase $(\lambda)$ were significantly higher for the
Table 8 Duration (days) of the pre-oviposition and oviposition periods of Helicoverpa armigera reared on sunflower genotypes and an artificial diet

\begin{tabular}{lll}
\hline Diets & Pre-oviposition period (days) & Oviposition period (days) \\
\hline ADV5504 & $1.5 \pm 0.27 \mathrm{a}^{\mathrm{a}}$ & $6.7 \pm 1.29 \mathrm{a}$ \\
CF101 & $1.6 \pm 0.22 \mathrm{a}$ & $7.5 \pm 0.96 \mathrm{a}$ \\
Helio 250 & $1.6 \pm 0.36 \mathrm{a}$ & $7.3 \pm 0.88 \mathrm{a}$ \\
Helio 251 & $1.6 \pm 0.24 \mathrm{a}$ & $7.7 \pm 1.67 \mathrm{a}$ \\
Helio 253 & $1.3 \pm 0.19 \mathrm{a}$ & $7.4 \pm 1.19 \mathrm{a}$ \\
Artificial diet & $1.9 \pm 0.32 \mathrm{a}$ & $7.7 \pm 0.62 \mathrm{a}$ \\
\hline
\end{tabular}

${ }^{a}$ Mean \pm standard error values followed by the same letter in the column are not significantly different (Tukey's test, $P>0.05$ ) 
Table 9 Fecundity (eggs/female) of Helicoverpa armigera reared on sunflower genotypes and an artificial diet

\begin{tabular}{ll}
\hline Diets & Fecundity (eggs/female) \\
\hline ADV5504 & $460.5 \pm 78.97 \mathrm{a}^{\mathrm{a}}$ \\
CF101 & $444.0 \pm 77.75 \mathrm{a}$ \\
Helio 250 & $542.6 \pm 84.22 \mathrm{a}$ \\
Helio 251 & $439.4 \pm 67.8 \mathrm{a}$ \\
Helio 253 & $485.5 \pm 96.94 \mathrm{a}$ \\
Artificial diet & $794.5 \pm 142.4 \mathrm{a}$
\end{tabular}

${ }^{\text {a }}$ Mean \pm standard error values followed by the same letter in the column are not significantly different (Tukey's test, $P>0.05$ )

Table 10 Fertility and incubation period of Helicoverpa armigera eggs laid by females reared on sunflower genotypes and an artificial diet

\begin{tabular}{lll}
\hline Diets & Egg fertility $(\%)$ & Incubation period of eggs (days) \\
\hline ADV5504 & $52.4 \pm 6.51 \mathrm{~b}^{\mathrm{a}}$ & $3.0 \pm 0.15 \mathrm{a}$ \\
CF101 & $53.7 \pm 3.61 \mathrm{~b}$ & $3.0 \pm 0.09 \mathrm{a}$ \\
Helio 250 & $57.7 \pm 3.21 \mathrm{ab}$ & $2.9 \pm 0.08 \mathrm{a}$ \\
Helio 251 & $56.2 \pm 5.44 \mathrm{ab}$ & $3.0 \pm 0.11 \mathrm{a}$ \\
Helio 253 & $49.9 \pm 4.74 \mathrm{~b}$ & $2.9 \pm 0.05 \mathrm{a}$ \\
Artificial diet & $73.8 \pm 2.96 \mathrm{a}$ & $2.8 \pm 0.06 \mathrm{a}$
\end{tabular}

${ }^{a}$ Mean \pm standard error values followed by the same letter in the column are not significantly different (Tukey's test, $P>0.05$ )

artificial diet at 0.193 female per female each day and 1.212 female per female each day, respectively. Among the sunflower genotypes, the highest rates of population growth were obtained for the Helio 250 genotype, with the values of 0.161 females per female each day and 1.175 female per female each day, respectively. The time for the population to double in size $(D t)$ was significantly shorter for the artificial diet, and only 3.6 days were required for population to double in number, which means that the number of eggs that the females will oviposit in 3.6 days will double the number of individuals of population. For sunflower genotypes, the shortest doubling time was obtained when the larvae were reared on genotype Helio 250 (4.3 days) (Table 11).

The fertility life table for $H$. armigera also shows that the artificial diet resulted in a higher rate of reproduction, indicating the production of a larger number of offspring per generation. Among the sunflower genotypes, Helio 250 presented the highest net reproductive rate, the shortest $D t$, and the highest rate of population growth, compared to other genotypes (Table 11).

In previous studies, the life table parameters of $H$. armigera on soybean genotypes ranged from 16.0 to 270.0 females per female and 0.084 to 0.114 females per female each day (Soleimannejad et al. 2010). These results indicate that $H$. armigera produces progeny and their population increases in both major crops such as soybean, as in off-crops such as sunflower, in which $R_{0}$ values obtained ranged from 62.9 to 255.9 females per female and $r_{\mathrm{m}} 0.141$ to 0.193 females per female each day, respectively.

The influence of host crop on insect growth could be due to differential rates of growth on various host plants, because of the differences in their nutritional quality and the amounts of secondary metabolites (Kranthi et al. 2003; SafuraieParizi et al. 2014). In the present study, the cultivars ADV5504 and CF101 were the ones that affected the egg fertility, production of offspring, and the population growth of $H$. armigera, resulting in a lower population growth in relation to other genotypes in the next generations of the insect. The observed responses to the mentioned parameters may be related to active chemical compounds metabolized by the plant, which become physiological toxins and cause the classic antibiosis or deterrent substances that avoid feeding the insect, reducing their survival (Liu et al. 2006; Shao-Ying et al. 2013). However, in the present work, no chemical analyses of the cultivars were carried out to allow conclusions on these aspects.

Development of improved crop varieties with resistance or tolerance to $H$. armigera is highly desirable, particularly

Table 11 Fertility life table parameters of Helicoverpa armigera reared on genotypes sunflower and artificial diet

\begin{tabular}{lrllll}
\hline Diets & \multicolumn{1}{c}{$R_{0}$} & $r_{\mathrm{m}}$ & $\lambda$ & $T$ & \multicolumn{1}{c}{ Dt } \\
\hline ADV5504 & $62.9 \pm 27.67 \mathrm{c}^{\mathrm{a}}$ & $0.141 \pm 0.0139 \mathrm{c}$ & $1.151 \pm 0.0160 \mathrm{c}$ & $29.5 \pm 0.86 \mathrm{ab}$ & $4.9 \pm 0.49 \mathrm{a}$ \\
CF101 & $83.5 \pm 33.07 \mathrm{bc}$ & $0.145 \pm 0.0139 \mathrm{c}$ & $1.157 \pm 0.0160 \mathrm{c}$ & $30.5 \pm 1.58 \mathrm{a}$ & $4.7 \pm 0.46 \mathrm{a}$ \\
Helio 250 & $135.6 \pm 46.91 \mathrm{~b}$ & $0.161 \pm 0.0087 \mathrm{~b}$ & $1.175 \pm 0.0103 \mathrm{~b}$ & $30.5 \pm 1.50 \mathrm{a}$ & $4.3 \pm 0.23 \mathrm{~b}$ \\
Helio 251 & $92.5 \pm 32.02 \mathrm{~b}$ & $0.144 \pm 0.0093 \mathrm{c}$ & $1.155 \pm 0.0107 \mathrm{c}$ & $31.4 \pm 2.95 \mathrm{a}$ & $4.8 \pm 0.30 \mathrm{a}$ \\
Helio 253 & $92.4 \pm 35.89 \mathrm{~b}$ & $0.146 \pm 0.0133 \mathrm{c}$ & $1.157 \pm 0.0153 \mathrm{c}$ & $31.1 \pm 1.46 \mathrm{a}$ & $4.7 \pm 0.43 \mathrm{a}$ \\
Artificial diet & $255.9 \pm 53.24 \mathrm{a}$ & $0.193 \pm 0.0206 \mathrm{a}$ & $1.212 \pm 0.0246 \mathrm{a}$ & $28.9 \pm 1.26 \mathrm{~b}$ & $3.6 \pm 0.39 \mathrm{c}$ \\
\hline
\end{tabular}

\footnotetext{
${ }^{a}$ Means \pm confidence interval (95\%) values followed by the same letter in the column are not significantly different (Student's $t$ test to compare group pairs, $P>0.05) . R_{0}=\Sigma$ (lx.mx), female offspring per female per generation, when $x=$ specific age, $l x=$ proportion of mated females alive at age $x, x=$ number of eggs produced per female at age $x$ multiplied by the sex ratio (sex ratio: $0.48,0.47,0.50,0.39,0.48$, and 0.37 for Helio 251, CF 101, Helio 250, ADV 5504, Helio 253, and the artificial diet, respectively); $T=\sum$ (x.lx.mx)/ $\sum(\operatorname{lx} . \mathrm{mx}) ; r_{\mathrm{m}}=\ln R_{0} / T ; \lambda=\mathrm{e}^{\mathrm{rm}}$; $D t=\ln (2) / r_{\mathrm{m}}$
} 
for the subsistence farming systems in the developing countries (Paramasiva et al. 2014). Furthermore, in pest management programs the host resistance is compatible with the other control tactics as biopesticides (Jarrahi and Safavi 2016), natural insecticide (Ahmad et al. 2015), and chemical control (Voujoudi et al. 2017).

\section{Conclusions}

Helicoverpa armigera has no preference between the sunflower genotypes evaluated. Thirty-five minutes in the multiple-choice test and $60 \mathrm{~min}$ in the no-choice test were the shortest time for larvae to discriminate among genotypes. Sunflower genotypes negatively affected the larval period and pupal weight of $H$. armigera compared with the artificial diet, but did not compromise development. The CF101 genotype had the lowest leaf area consumed and displayed the lowest results for $H$. armigera development.

Acknowledgements C. C. T. was supported by the Tutorial Education Program and fellowship from the Sao Paulo State University.

\section{References}

Abrol DP (2013) Integrated pest management: current concepts and ecological perspectives. Academic Press, San Diego, p 584

Ahmad S, Ansari MS, Muslim M (2015) Toxic effects of neem based insecticides on the fitness of Helicoverpa armigera (Hübner). Crop Prot 68:72-78

Baptista APM, Carvalho GA, Carvalho SM, Carvalho CF, Bueno Filho JSS (2009) Toxicidade de produtos fitossanitários utilizados em citros para Aphis melífera. Ciênc Rural 39:955-961

Birch LC (1948) The intrinsic rate of natural increase of on insect population. J Anim Ecol 17:15-26

Bueno RCOF, Yamamoto PT, Carvalho MM, Bueno NM (2014) Occurrence of Helicoverpa armigera (Hubner, 1808) on citrus in the state of Sao Paulo, Brazil. Rev Bras Frutic 36:520-523

Building BM, Arhabhata S (2007) Status of insecticide resistance in the cotton bollworm, Helicoverpa armigera (Hübner). J Cent Eur Agric 8:171-182

CONAB - Companhia Nacional de Abastecimento (2015) Boletim Conjuntura Mensal. Available at http://www.conab.gov.br/Ola laCMS/uploads/arquivos/15_07_14_14_15_03_girassoljunho2015. pdf. Accessed August 15, 2015

Cunningham JP, Zalucki MP, West SA (1999) Learning in Helicoverpa armigera (Lepidoptera: Noctuidae): a new look at the behavior and control of a polyphagous pest. Bull Entomol Res 89:201-207

Czepak C, Albernaz KC, Vivan LM, Guimarães HO, Carvalhais T (2013) Primeiro registro de ocorrência de Helicoverpa armigera (Hübner) (Lepidoptera: Noctuidae) no Brasil. Pesqui Agropecu Trop 43:110-113

Gabriel D (2013) Lagarta Helicoverpa: mais um sério problema. São Paulo: Instituto Biológico. (Comunicado Técnico, 186). Available at http://www.biologico.sp.gov.br/artigos_ok.php?id_ artigo $=186$. Accessed February 11, 2015

Gottems L (2014) Helicoverpa armigera ataca cana, citros e amendoim em São Paulo. Available at http://www.agrolink. com.br/culturas/milho/noticia/helicoverpa-armigera-ataca-canacitros-e-amendoim-em-sao-paulo_194355.html. Accessed February 19,2015

Greene GL, Leppla NC, Dickerson WA (1976) Velvetbean caterpillar: a rearing procedure and artificial medium. J Econ Entomol 69:487-488

Inácio FR, Marchini LC, Ambrosano GMB, Moreti ACCC (2003) Efeito da aplicação de inseticida carbamato na visitação de insetos e sua relação com a produtividade na cultura do girassol (Helianthus annuus L.) Rev Magistra 15:87-91

Jarrahi A, Safavi SA (2016) Fitness costs to Helicoverpa armigera after exposure to sub-lethal concentrations of Metarhizium anisopliae sensu lato: study on F1 generation. J Invert Pathol 138:50-56

Kranthi S, Krathi KR, Wanjari RR (2003) Influence of semilooper damage on cotton host-plant resistance to Helicoverpa armigera (Hub). Plant Sci 164:157-163

Krebs CJ (1994) Ecology: the experimental analysis of distribution and abundance, 4th edn. Harper Collins College Publishers, New York

Lara FM (1991) Princípios de resistência de plantas a insetos, 2nd edn. Ícone, São Paulo

Lazzarotto JJ, Roessing AC, Mello HC O (2005) Agronegócio do girassol no mundo e no Brasil. In: Campos Leite RMVB, Brighenti AM, Castro C (eds) Girassol no Brasil, Embrapa-Soja, Londrina, PR, Brazil, pp 15-42

Liu X, Liang P, Gao X, Shi X (2006) Induction of the cytochrome P450 activity by plant allelochemicals in the cotton bollworm, Helicoverpa armigera (Hübner). Pest Biochem Physiol 84:127-134

Maia AHN, Luiz AJB, Campanhola C (2000) Statistical inference on associated fertility life parameters using Jackknife technique: computational aspects. J Econ Entomol 93:511-518

MAPA-Agrofit (2015) Available at http://www.agricultura.gov.br/. Accessed February 11, 2015

Moretti AC, Parra JRP (1983) Biologia comparada e controle de qualidade de Heliothis virescens (Fabr., 1781) (Lepidoptera: Noctuidae) em dietas natural e artificial. Arq Inst Biol 50:7-15

Paramasiva I, Krishnayya PV, War AR, Sharma HC (2014) Crop hosts and genotypic resistance influence the biological activity of Bacillus thuringiensis towards Helicoverpa armigera. Crop Prot 64:38-46

Paro Júnior LA, Nakano O (1976) Dano simulado para a lagarta do girassol Chlosyne lacinia saundersii (Lepidoptera: Nymphalidae). An Soc Entomol Bras 5:216-294

Pratissoli D, Lima VLS, Pirovani VD, Lima WL (2015) Occurrence of Helicoverpa armigera (Lepidoptera: Noctuidae) on tomato in the Spirito Santo State. Hortic Bras 33:101-105

Price PW (1984) Insect ecology, 2nd edn. Wiley, New York

Safuraie-Parizi S, Fathipour Y, Talebi AA (2014) Evaluation of tomato cultivars to Helicoverpa armigera using two-sex life table parameters in laboratory. J Asia Pac Entomol 17:837-844

SAS Institute (2002) SAS: user's guide: statistics. Version 9.0. Cary

Shanower TG, Romeis J (1999) Insect pests of pigeon pea and their management. Annu Rev Entomol 44:77-96

Shao-Ying W, Xue-Yan S, Yi W, Xi-Wu G (2013) Response of cytochrome $\mathrm{P} 450$ expression to maize volatiles in Helicoverpa armigera (Hübner). J Integr Agric 12:646-652

Sharma M, Singh G (2001) Development of Helicoverpa armigera on different hybrids of sunflower (Helianthus annuus). Indian J Agric Sci 71:538-543

Silveira Neto S, Nakano O, Barbin D (1976) Manual de ecologia dos insetos. Agronômica Ceres, São Paulo

Soleimannejad S, Fathipour Y, Moharramipour S, Zalucki MP (2010) Evaluation of potential resistance in seeds of different soybean cultivars to Helicoverpa armigera (Lepidoptera: Noctuidae) 
using demographic parameters and nutritional indices. J Econ Entomol 103:1420-1430

Southwood TER (1978) Ecological methods. Chapman and Hall, London

USDA-United States Department of Agriculture (2015) Oilseeds: World Markets and Trade. Available at http://apps.fas.usda.gov/ psdonline/circulars/oilseeds.pdf. Accessed February 11, 2015
Villas Bôas GL, Moscardi F (1985) Levantamento dos insetos-pragas do girassol e seus inimigos naturais. Embrapa, Londrina

Voujoudi S, Saber M, Gharekhani G, Esfandiari E (2017) Toxicity and sublethal effects of hexaflumuron and indoxacarb on the biological and biochemical parameters os Helicoverpa armigera (Hubner) (Lepidoptera: Noctuidae). Crop Prot 91:100-107 